\title{
Analysis of the threshing process in the interriffle space of the threshing device
}

\author{
Elena Fisunova ${ }^{1, *}$, Leonid Groshev ${ }^{1}$, and Olga Baryshnikova ${ }^{1}$ \\ ${ }^{1}$ Don State Technical University, Gagarin square 1, Rostov-on-Don, 344000, Russia
}

\begin{abstract}
By implementing a factor experiment in the laboratory the regularity of the change in the degree of threshing of ears in the space between the riffles of the flail's threshing drum was stated. A mathematical model of the threshing process in the space between the riffles is given. The obtained results broaden the understanding of the nature of threshing by grinding in the threshing space of a combine harvester. The tests used unmilled ears of Donskaya ostistaya wheat, freed from grains by $70-80 \%$. It is determined that the complete threshing is carried out for one impact of the flail and with minimal compression of the plant mass. Conclusions are made about the results obtained.
\end{abstract}

To solve the problems of intensification of the process of interriffle threshing of bread mass and to optimize the parameters of the riffled surface of the flails we carried out a factorial experiment with responses rationale, selection of the independent variables and the establishment of their variation range. The main object was chosen underthreshed (25\%) ear, and the response is the degree of threshing of the ear after dragging between the riffles.

The number of influencing factors included: radius of the rounding of the trailing edge of the riffle, filling the interriffle channel with a different number of stems, moisture of bread mass. The polynomial of the second degree is chosen by us as the regression equation.

The realization of threshing was carried out on a functional device, the scheme of which is shown in Figure 1.

According to the conditions of the experiment, the stem with ear 4 was placed in the interriffle channel. The ear of the stem was fixed by a clamping device 5 with an extended spring 6 , with fixation of the position by the stopper 7 . The parameters of the spring and the position of the clamp are chosen so that the center of the ear goes at the maximum speed to the middle of the flail. The working edges of the riffles have different radiuses of rounding. In the initial position, the flail 1 presses the load $2(\mathrm{Q}=2 \mathrm{~kg})$ to the mat from the stems 3 .

* Corresponding author: fis62@mail.ru 


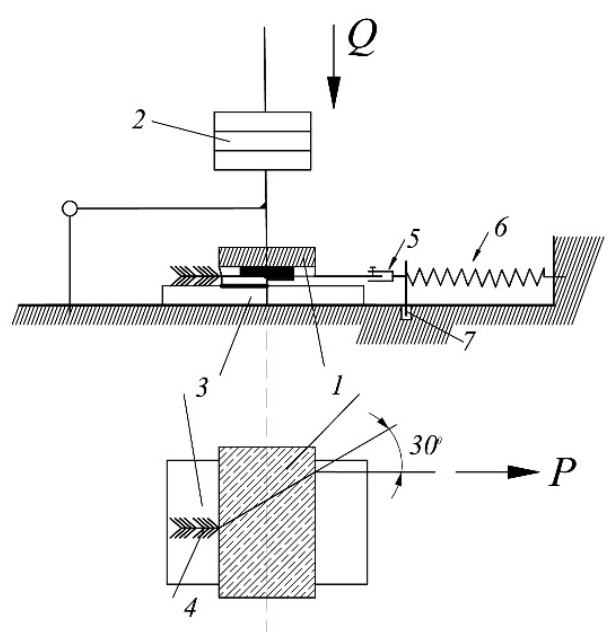

Fig. 1. Schematic scheme of the device: 1 - flail; 2 - load; 3 - Mat (tied stems); 4 - ear with stem; 5 clamping device; 6 - spring; 7 - stopper.

With the release of the spring, there was a complete or partial separation of the grains from the ear rod of homogeneous wheat stalks with an average stalk diameter of $4 \mathrm{~mm}$. Stems bound in the transverse direction were used in the experiment as a supporting surface. Factors and levels of their variation are presented in the table 1.

Table 1. Factors and levels of their variation

\begin{tabular}{|c|c|c|c|c|c|c|}
\hline Factors & $\begin{array}{c}\text { Code } \\
\text { Symbol }\end{array}$ & $\boldsymbol{X}_{\boldsymbol{i}}=\mathbf{- 1 . 2 1 5}$ & $\boldsymbol{X}_{\boldsymbol{i}}=\mathbf{- 1}$ & $\boldsymbol{X}_{\boldsymbol{i}}=\mathbf{0}$ & $\boldsymbol{X}_{\boldsymbol{i}}=\mathbf{+ 1}$ & $\begin{array}{c}\boldsymbol{X}_{\boldsymbol{i}}= \\
\mathbf{+ 1 . 2 1 5}\end{array}$ \\
\hline $\begin{array}{c}\text { Edge } \\
\text { rounding } \\
\text { radius R, } \\
\text { mm }\end{array}$ & $X_{1}$ & 0.785 & 1 & 2 & 3 & 3.215 \\
\hline $\begin{array}{c}\text { Degree of } \\
\text { filling the } \\
\text { channel } \\
\delta, \text { mm }\end{array}$ & $X_{2}$ & 9.86 & 12.56 & 25.12 & 37.68 & 40.38 \\
\hline $\begin{array}{c}\text { Moisture W, } \\
\%,(\mathrm{~min})\end{array}$ & $X_{3}$ & $8.71(0)$ & $\begin{array}{c}10 \\
(8.6)\end{array}$ & $\begin{array}{c}16 \\
(18.6)\end{array}$ & $\begin{array}{c}22 \\
(88.6)\end{array}$ & $\begin{array}{c}23.29 \\
(97.2)\end{array}$ \\
\hline
\end{tabular}

The regression equation has the form:

$$
\begin{gathered}
Y=54.80-7.92 X_{1}+1.6 X_{2}-0.69 X_{3}+8.92 X_{1}^{2}-7.56 X_{2}^{2}-6.07 X_{3}^{2}+15.63 X_{1} X_{2}- \\
-0.51 X_{1} X_{3}-8.42 X_{2} X_{3}
\end{gathered}
$$

After processing the data sets, the obtained estimates allow us to state that the regression equation adequately reflects the threshing process. Eliminating insignificant coefficients, equation (1) assumed the form:

$$
Y=54.80-7.92 X_{1}+8.92 X_{1}^{2}-7.56 X_{2}^{2}+15.63 X_{1} X_{2}-8.42 X_{2} X_{3}
$$


Analysis of the equation involves two options that favor the growth of the response. When the values $X_{1}=+1, X_{2}=+1, X_{3}=-1$ were substituted into the equation we got:

$$
Y=54.80-7.92+8.92-7.56+15.63+8.42=72.29
$$

After substituting the values $X_{1}=-1, X_{2}=-1, X_{3}=+1$ found

$$
Y=54,80+7,92+8,92-7,56+15,63+8,42=88,13
$$

From the expression (3) we conclude that the threshing proceeds more efficiently with the largest values of the edge rounding radius and the degree of filling of the interriffle cavity, if the bread mass is less moist. It follows from expression (4) that the threshing passes more efficiently when the interriffle channel are not filled with stems and with the minimum rounding radius of the edge when threshing the more moist bread mass. It should be noted that the grain in the ear, facing the edge of the riffle, is separated more easily [7-8].

\section{Summary}

Threshing of unmilled ears reaches $70-90 \%$ in the interriffle channel with a single hit of the flail. The effectiveness of threshing is higher, the smaller the radius of rounding and the degree of filling of the interriffle channel for a more moist bread mass, and the larger the radius and degree of filling of the interriffle space for the less moist plant mass. The results obtained can be used to optimize the parameters of the corrugated surface.

\section{References}

1. N.I. Klenin, Research of the milling and separation of grain, 424 (1977)

2. G.A. Kuzin, Intensification of threshing and separation process in threshing machines of combine harvesters, 505 (1989)

3. C. Kanadfoiski, Grundlagen erntetechnishen Baugruppen, 2, 312 (1973)

4. N.I. Chursin, Research of technological process in rotary threshers of harvesting machines, 295 (1970)

5. A.A. Bachterev, G.A. Iovlev, A.G. Nesgovorov, TIPMN, Perfection of the process of threshing grain crops, 10, 51-60 (2017)

6. M.M. Konstantinov, I.N. Glushkov, I.V. Gerasimenko, A.A. Panin, V.I. Kvashennikov, A.P. Lovchikov, IOGAU, Evaluation of qualitative indicators of the formation of bread rolls, their selection and threshing when using a portioning header on separate harvesting of cereals, 6 (62), 68-72 (2016)

7. N.I. Kosilov, DNITAPK, Two-phase threshing in domestic and foreign combinebuilding, 8, 3-5 (2006)

8. M.I. Lipovski, DNITAPK, Rational two-phase threshing, 8, 3-5 (2006) 